\title{
ANLIK GÜÇ ŞIDDET ÖLÇÜSÜNÜN YAKIN SAHA YER HAREKETINE MARUZ KALAN YAPILARIN MAKSIMUM VE KÜMÜLATIF TEPKILERINI TAHMIN ETMEDEKI ETKINLIĞi
}

\author{
Esra ZENGIN*
}

\section{ÖZ}

Yakın zamanda önerilen Anlık Güç (IP(T1)) şiddet ölçüsünün, hız darbeli yakın saha yer hareketlerinin yıkıcı etkilerini yakaladığı gösterilmiştir. Bu çalışma, yapının temel periyodundaki elastik spektral ivme (Sa(T1)) ve IP(T1)'den oluşan vektör şiddet ölçüsünün, maksimum ve kümülatif yapısal tepkileri içeren farklı hasar parametrelerini tahmin etmedeki etkinliğini araştırmayı amaçlamaktadır. Farklı şiddet seviyelerinde 40 adet darbeli ve darbesiz deprem kaydına maruz kalan 9 katlı çelik çerçeve yapının maksimum göreli kat ötelenmeleri ve değiştirilmiş Park ve Ang hasar indisleri incelenmiştir. Darbe periyotlarının yanı sıra skaler ve vektör şiddet ölçülerinin doğrusal olmayan yapısal tepkiler üzerindeki etkileri değerlendirilmiştir. Sonuçlar, [Sa(T1), IP(T1)] vektör şiddet ölçüsünün, maksimum ve kümülatif yapısal tepkileri tahmin etmede etkin olduğunu göstermiştir.

Anahtar Kelimeler: yakın saha yer hareketi; şiddet ölçüsü; hız darbeli deprem kayıtları; sismik hasar

*Makalenin Gönderim Tarihi:21.04.2021, Kabul Tarihi:16.06.2021, Araştırma, DOI: 10.20854/bujse.924341

*Sorumlu yazar: Beykent Üniversitesi, Mühendislik ve Mimarlık Fakültesi İnşaat Mühendisliği Bölümü, İstanbul, Türkiye, esrazengin@beykent.edu.tr 


\title{
EFFECTIVENESS OF THE INSTANTANEOUS POWER IN PREDICTING PEAK AND CUMULATIVE RESPONSES OF STRUCTURES UNDER NEAR-FAULT GROUND MOTIONS
}

\author{
Esra ZENGIN*
}

\begin{abstract}
A recently proposed intensity measure (IM), Instantaneous Power (IP(T1)), has been shown to capture the destructive potential of the near-fault ground motions including velocity pulses. This study aims to investigate the effectiveness of the vector intensity IM consisting of elastic spectral acceleration at the fundamental period of structure $(\mathrm{Sa}(\mathrm{T} 1))$ and $\mathrm{IP}(\mathrm{T} 1)$, in predicting different damage parameters, including peak and cumulative structural responses. We investigate the maximum interstory drift ratios (MIDRs) and Modified Park and Ang Damage Index (DI) of 9-story steel frame structure subjected to 40 pulse-like and non-pulse-like earthquake records at different IM levels. We evaluate the effects of pulse periods as well as scalar and vector IMs on nonlinear structural responses. The results demonstrate that the vector $[\mathrm{Sa}(\mathrm{T} 1), \mathrm{IP}(\mathrm{T} 1)]$ can be used as an effective IM for predicting the peak-and cumulative-based structural responses.
\end{abstract}

Keywords: Near-fault ground motion; intensity measure; pulse-like earthquake records; seismic damage. 


\section{GíRiş}

Yakın saha depremleri üzerine yapılan çalışmaların çoğu ileri yönelim etkisinden kaynaklı hız darbelerini karakterize etmeye odaklanmıştır. İleri yönelim etkisi, kırılma cephesinin kayma dalgası hızına yakın bir hızla sahaya doğru hareket ettiği durumda oluşmaktadır. Kısa bir süre içinde büyük bir enerjinin sahaya ulaştığı bu etkide hız-zaman serisinde belirgin bir darbe oluşmaktadır (Somerville, Smith, Graves, \& Abrahamson, 1997). Hız darbesi içeren yakın saha yer hareketlerinin karakteristik özelliklerinin uzak saha deprem kayıtlarından farklı olduğu görülmüştür. Örneğin, bu sinıfta yer alan yer hareketlerinin yıkıcı etkileri darbe periyodu (Tp) ve darbe genliği ile karakterize edilmektedir. Bilindiği üzere, yapıların depreme karşı davranışını değerlendirmede depremin genlik ve frekans içeriği gibi özelliklerini temsil eden şiddet ölçüsü kullanılmaktadır. Yapının temel (ilk) periyodunda hesaplanan elastik spektral ivme (Sa(T1)) yapısal tepkiyi tahmin etmede yaygın olarak kullanılan bir şiddet ölçüsüdür. $\mathrm{Sa}(\mathrm{T} 1)$, birinci modu baskın yapıların deprem taleplerini tahmin etmede iyi bir performans göstermesine rağmen doğrusal olmayan davranıs sırasında periyot uzama etkilerini veya yüksek mod katkılarını temsil edememektedir. Ayrıca, hız darbesi içeren yakın saha yer hareketinin yüksek deplasman talebinin ve ağır hasar yaratma potansiyelinin $\mathrm{Sa}(\mathrm{T} 1)$ tarafından yakalanamadığı görülmüştür (Alavi \& Krawinkler, 2000).

Geçmiş çalışmalarda yakın saha yer hareketine maruz kalan yapıların tepkilerini daha doğru ve etkili tahmin edebilmek için gelişmiş skaler ve vektör şiddet ölçüleri önerilmiştir (Luco \& Cornell, 2007) (Tothong \& Luco, 2007). Bir şiddet ölçüsünün performansı genellikle yapısal tepki tahminindeki verimliliği ve yeterliliği açısından değerlendirilmektedir. Yeterlilik, şiddet ölçüsünün depremin diğer sismolojik özelliklerinden (örneğin büyüiklük ve mesafe) bağımsız yapısal tepkiyi tahmin etme yeteneğini ifade ederken, verimlilik kavramı, bir şiddet ölçüsünün yapısal tepkinin değişkenliğini ne kadar azalttığını göstermektedir. Yapısal tepkiyle yüksek korelasyon gösteren etkili bir şiddet ölçüsü, dinamik analizlerde daha az sayıda yer hareketiyle yapısal performansı güvenilir bir şekilde tahmin etmemize olanak sağlar. $\mathrm{Sa}(\mathrm{T} 1)$ şiddet ölçüsünün yakın saha depremlerinin taleplerini tahmin etmedeki yetersizliğini gidermek için $\mathrm{Sa}(\mathrm{T} 1)$ ve Anlık Güçten (IP(T1)) oluşan yeni bir vektörel şiddet ölçüsü [Sa (T1), IP(T1)] önerilmiştir (Zengin \& Abrahamson, 2020a). IP(T1), bant filtreli hız serisinin kısa bir zaman aralığındaki maksimum gücünü ifade etmektedir. IP(T1 parametresi darbe periyodunun yapı üzerindeki etkisini yakalayabildiği için yakın saha deprem kayıtlarının seçiminde ikincil şiddet ölçüsü olarak kullanılan Tp'nin yerine alternatif olarak kullanılmaktadır. Buna ek olarak, vektör-bazlı olasılıksal sismik tehlike analizlerinde kullanılarak yapıların sismik risk tahminine olanak sağlaması için IP(T1) koşullu yer hareketi modeli önerilmiştir (Zengin \& Abrahamson, 2020b).

Bu çalışmada, Anlık Güç yer hareketi şiddet ölçüsünün maksimum ve kümülatif yapısal tepki parametrelerinin tahminindeki performansı değerlendirilmiştir. 9 katlı çelik çerçevenin doğrusal olmayan dinamik analizleri darbeli ve darbesiz yakın saha yer hareketleri altında gerçekleştirilmiştir. Skaler $\mathrm{Sa}(\mathrm{T} 1)$ ve vektör $[\mathrm{Sa}(\mathrm{T} 1)$, IP(T1)] şiddet ölçülerinin yapının maksimum göreli kat ötelenmelerini (MKÖ) ve değiştirilmiş Park and Ang hasar indisini (Kunnath, Reinhorn, \& Lobo, 1992) tahmin etmedeki etkinliği incelenmiştir.

\section{ANLIK GÜÇ ŞIDDET ÖLÇÜSÜ}

Filtrelenmiş hız serisinin kısa zaman aralığındaki maksimum gücünü (enerji değişim oranı) temsil eden IP(T1), aşağıdaki denklem kullanılarak elde edilebilir.

$$
I P\left(T_{1}\right)=\operatorname{maks}\left(\frac{1}{0.5 T_{1}} \int_{t_{0}}^{t_{0}+0.5 T_{1}} V_{\text {filtre }}^{2}(t) d t\right)
$$

Bu denklemde $\mathrm{V}$ _filtre, $\mathrm{cm} / \mathrm{s}$ cinsinden bant filtreli yer hareketinin hızıdır. $0.5 \mathrm{~T} 1$ yapının temel periyodunun yarısını ifade etmekte ve anlık gücü hesaplamadaki pencere uzunluğunu temsil etmektedir. Hız serisine 0.2T1- 3T1 periyot bant aralığında dört kutuplu Butterworth filtre uygulanmış ve böylelikle yapıyı etkileyecek frekans içeriği göz önüne alınmıştır. Şekil 1, 1979 Imperial Valley-06 Kaliforniya depremi Agrarias istasyonuna ait darbeli kaydın filtrelenmiş ve orijinal hız-zaman serilerini göstermektedir. Bu kayıt için maksimum IP değerinin depremin yaklaşık 10 . saniyesinde gerçekleştiği görülmüştür.

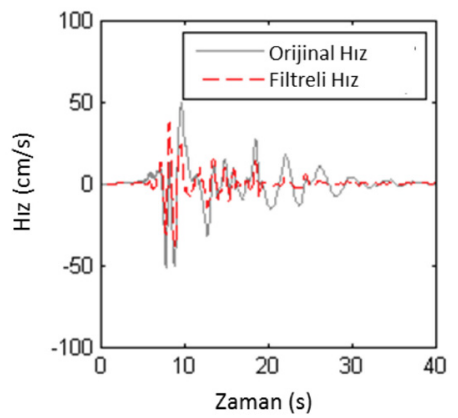

Şekil 1. 1979 Imperial Valley-06 Kaliforniya depremi Agrarias istasyonuna ait darbeli kaydın filtrelenmiş ve orijinal hız-zaman serileri. 


\section{YER HAREKETI VERITABANI}

Darbeli ve darbesiz yakın saha deprem kayıtlarını seçmek için Pasifik Deprem Mühendisliği Araştrma Merkezi (PEER) Kuvvetli Yer Hareketi veri tabanı, deprem büyüklüğü $5.5-8.5$ ve kırlma mesafesi $0-30 \mathrm{~km}$ aralıklarında olacak şekilde sınırlandırılmıştır. Darbeli ve darbesiz kayıtların seçiminde spektral şekilleri benzer kayit çiftleri seçilmiştir (Zengin, Abrahamson, \& Kunnath, 2020). Böylece, her iki kayit grubunun ortalama spektrum değerleri sabit tutulmuştur. Yapıyı daha önemli ölçüide etkileyecek frekans içeriğini göz önüne almak için darbeli kayıt TP'sinin [0.5T1-3T1] periyot aralığında olmasina dikkat edilmiştir. Şekil 2'de seçilen darbeli ve darbesiz 40 adet deprem kaydının medyan ve medyan+1sigma elastik ivme spektrumları gösterilmektedir.

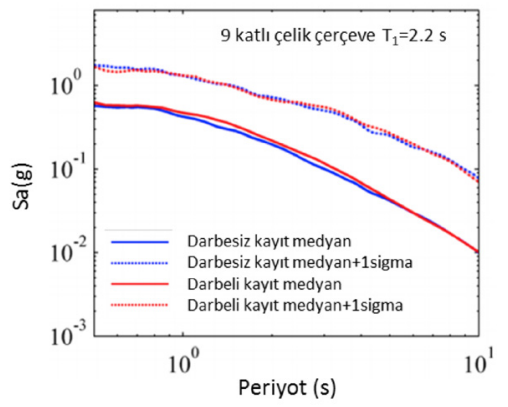

Şekil 2. Spektral şekilleri eşdeğer 40 darbeli ve darbesiz kayıt spektrumlarının medyan ve medyan+1sigma değerlerinin karşılaştırılması.

\section{BINA MODELI}

Bu çalışmada, Los Angeles Kaliforniya'da bulunan 9 katlı çelik bina kullanılmıștır (Zengin, Abrahamson, \& Kunnath, 2020). 2001 Kaliforniya Bina yönetmeliği esaslarına göre tasarlanan binanın cepheden görünüşü Şekil 3'te gösterilmektedir. Kat yükseklikleri, açıklık uzunlukları ve yapının kirişlerinin ve kolonlarııın kesitleri Şekil 3'te verilmiştir. Yapının doğrusal olmayan modeli OpenSees yazılımı kullanılarak elde edilmiştir. Kiriş ve kolon birleşimlerinde dayanım ve rijitlik azalımını dikkate alan değiştirilmiş Ibarra Medina Krawinkler (ModIMK) malzemesi modeli tanımlanmış yaylar kullanılmıștı. Bu histeretik model, yapısal elemanın statik monotonik davranışını temsil eden başlangıç bir iskelet eğrisi ve bu iskelet eğrisinin yükleme geçmişine bağlı bozulumunu temsil eder. Șekil 4 'te gösterilen ModIMK histeretik modelinin iskelet eğrisi, akma dayanımı (fy), akma deformasyonu (uy), tepe noktası deformasyonu (uc), akma sonrası rijitlik oranı $(\alpha s)$ ve tepe noktası sonrası rijitlik oranı $(\alpha c)$ ile tanımlanır. İskelet eğrisinde görüldü̆ğü üzere tepe noktasına ulaştıktan sonra eğim negatif olur ve elemanın dayanımı 'artık dayanıma' kadar düşer.

$\mathrm{Bu}$ çalışmada, $\alpha \mathrm{s}=0.10$ ve artık dayanım faktörü $(\lambda)$ 0.40 olarak kabul edilmiştir. Diğer parametreler, her bir eleman için ayrı ayrı hesaplanmıştır. Bu model hakkındaki daha detaylı bilgiye ve parametrelerin hesabı için önerilen ampirik denklemlere Ibarra, Medina ve Krawinkler (2005) tarafindan yazilan makaleden ve Lignos (2008) tarafindan yazilan tezden ulaşlabilir Analitik modelde P-Delta etkilerini simüle etmek için bina yüklerinin yarısı eșdeğer ağırlık çerçevesine etki ettirilmiş ve bu ağırllık çerçevesi taşıııcı sisteme rijit elemanlarla bağlanmıştır. Yapısal modelin birinci periyodu 2.20 saniye olarak bulunmuştur.

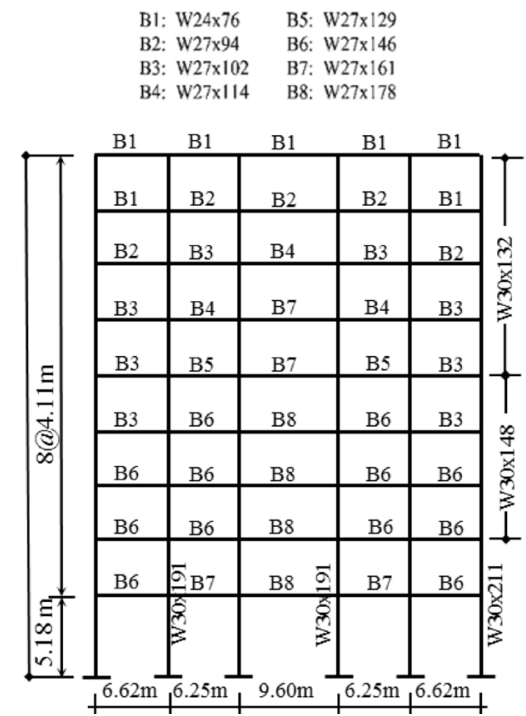

Şekil 3. 9 katlı çelik binanın cephe görünüşü. Kiriş ve kolon kesitleri.

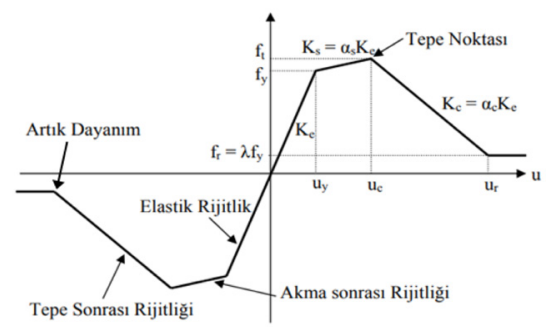

Şekil 4. Değiştirilmiş ModIMK histeretik modeli iskelet eğrisi 


\section{DARBELI VE DARBESIZ KAYITLARIN YAPI TEPKISINE ETKISI}

Literatürdeki çalışmalar hız darbesinin yapı üzerindeki etkisinin darbe periyodunun yapının periyoduna oranına (Tp/T1) göre değiştiğini göstermiştir (Alavi \& Krawinkler, 2000) (Baker \& Cornell, 2008). Örneğin, $(\mathrm{Tp} / \mathrm{T} 1>2)$ olan darbeli yer hareketlerinin yüksek hasar potansiyeline sahip olduğu düşünülmektedir. Bunun nedeni, yüksek yer hareketi şiddetine maruz kalan binada doğrusal olmayan davranış nedeniyle periyodun uzaması ve darbeli yer hareketinin periyodu ile çakışmasıdır. Ancak, literatürdeki çalışmalar (Tp/T1) parametresinin darbeli yer hareketlerinin yıkıcı etkilerini tanımlamada yetersiz olduğunu, bu depremlerin hasar potansiyellerinin yapının özelliklerine ve yer hareketinin şiddetine göre değiştiğini göstermiştir. Aynı zamanda, darbesiz yakın saha yer hareketlerinin darbeli yer hareketlerinden daha yıkıcı olduğu durumlar da gözlemlenmiştir.

$\mathrm{Tp} / \mathrm{T} 1$ parametresinin yapı üzerindeki etkisini daha detaylı araştırmak için yer hareketleri $(\mathrm{Tp} / \mathrm{T} 1<1)$, $(1<\mathrm{Tp} / \mathrm{T} 1<2)$ ve $(\mathrm{Tp} / \mathrm{T} 1>2)$ olmak üzere üç gruba ayrılmıştır. Her darbeli kaydın spektral şekliyle uyumlu darbesiz kayıt da seçildiğinden, darbesiz kayıtların yapı üzerindeki etkisi de incelenmiştir. Bu çalışmada, yapısal hasarı temsilen MKÖ ve değiştirilmiş Park ve Ang hasar indisi kullanılmaktadır. Kullanılan hasar indisi plastik deformasyonun katkısını ve toplam histeretik enerji kaybını göz önüne aldığı için kümülatif hasar etkisini göstermektedir. Şekil 5 ve Şekil 6 tepki parametrelerinin bina katları boyunca değişimini göstermektedir. Sahaya özgü olasılıksal sismik tehlike analiz sonucunda 50 y1l içinde aşılma olasılığı \%2 olan deprem seviyesinde hedef $\mathrm{Sa}(\mathrm{T} 1=2.2 \mathrm{~s})$ değeri $0.30 \mathrm{~g}$ olarak belirlenmiştir. $\mathrm{Bu}$ çalışmada, düşük ve yüksek yer hareketi şiddetini temsilen kayıtların $\mathrm{Sa}(\mathrm{T} 1)$ değerleri $0.2 \mathrm{~g}$ 'ye ve $0.4 \mathrm{~g}$ 'ye ölçeklendirilmiştir.

Yer hareketi şiddet ölçüsünün $\mathrm{Sa}(\mathrm{T} 1)=0.2 \mathrm{~g}$ olduğu durum düşük deprem seviyesini temsil ettiği için yapısal tepki parametrelerinin değerleri yüksek deprem seviyesindeki değerlerine $(\mathrm{Sa}(\mathrm{T} 1)=0.4 \mathrm{~g})$ göre düşüktür. $0.2 \mathrm{~g}$ 'de maksimum kat ötelenmesi ve hasar indisi yapısal parametrelerinin maksimum değerlerine 6 . kat seviyesinde ulaşılmıştır. $(\mathrm{Tp} / \mathrm{T} 1<1)$ yer hareketi grubunun bu şiddet ölçüsünde diğer kayıt gruplarına göre yüksek sonuçlar verdiği görülmektedir. İnelastik deformasyonlar düşük yer hareketi şiddetinde sinırlı olduğu için, yüksek hasar yaratması beklenen (Tp/T1>2) kayıt grubunun yapıda önemli bir hasar yaratmadığı görülmüştür. Aynı zamanda, maksimum tepkilerin yüksek katlarda gerçekleşmesi $(\mathrm{Tp} / \mathrm{T} 1<1)$ kayıt setinin yüksek modları harekete geçirdiğini göstermektedir.

Yüksek yer hareketi şiddetinde $(0.4 \mathrm{~g})$, yapıda büyük inelastik deformasyonlar oluşmuş ve maksimum kat ötelenmeleri $(\mathrm{Tp} / \mathrm{T} 1>2)$ kayıt seti için yaklaşı \%3 değerine ulaşmıştır. Ancak, kümülatif histeretik enerji kayıplarının etkisini de göz önüne alan hasar indisi için maksimum değerler yapının rijitliğinin değiştiği 6. katta görülmüştür. Bunlara ek olarak, bu yapısal tepki parametresi için darbesiz kayıtların darbeli kayıtlara göre daha hasar verici olduğu görülmüştür. $\mathrm{Bu}$ sonuçlar, darbe periyodunun hasar etkisinin, yer hareketinin şiddetine ve analizlerde kullanılan yapı tepki parametresine göre değiştiğini göstermektedir.
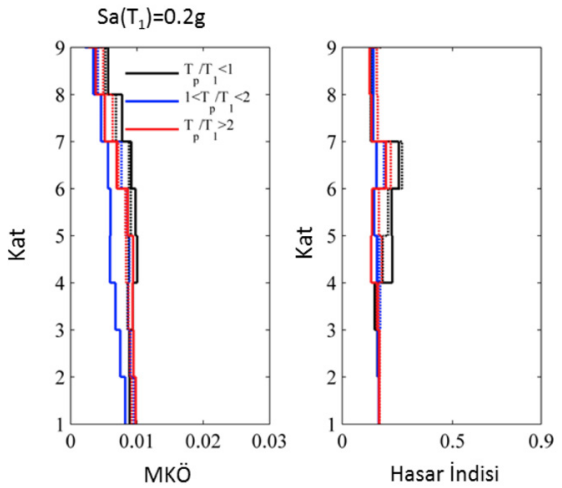

Şekil 5. Darbe periyoduna göre gruplandırılmış darbeli kayıt setlerinin $0.2 \mathrm{~g}$ elastik spektral ivme şiddetinde maksimum göreli kat ötelenmesi (MKÖ) ve değiştirilmiş Park ve Ang hasar indisi üzerindeki etkisi.

Darbesiz kayıt setleri kesik çizgi ile gösterilmiştir.
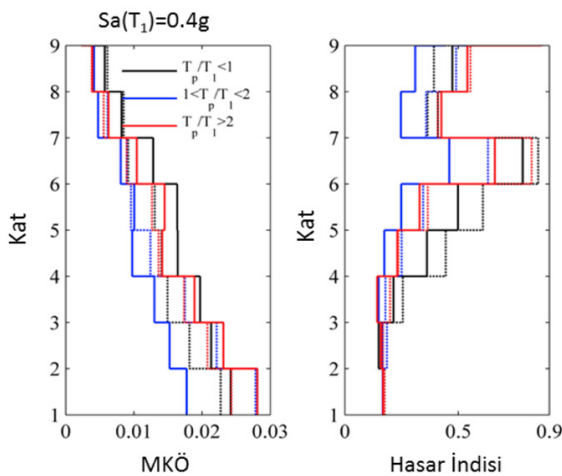

Şekil 6. Darbe periyoduna göre gruplandırılmış darbeli kayıt setlerinin $0.4 \mathrm{~g}$ elastik spektral ivme şiddetinde maksimum göreli kat ötelenmesi (MKÖ) ve değiştirilmiş Park ve Ang hasar indisi üzerindeki etkisi.

Darbesiz kayıt setleri kesik çizgi ile gösterilmiştir. 


\section{ANLIK GÜÇPARAMETRESININETKINLIIĞI}

Yüksek yer hareketi şiddeti seviyesi $\mathrm{Sa}(\mathrm{T} 1)=0.4 \mathrm{~g}$ 'ye ölçeklendirilmiş darbeli ve darbesiz kayıtların yapısal tepkilerinin $\mathrm{IP}(\mathrm{T} 1)$ ile korelasyonu Şekil 7'de gösterilmiştir. İki parametre arasındaki ilişkinin gücü, belirleme katsayısı (R2) ile değerlendirilmiştir. Sonuçların pratik önemini incelemek için Cohen'in kriteri kullanılmıştır (Cohen, 1988). Bu kritere göre R2 $=.01$ zaylf korelasyon etkisini, $\mathrm{R} 2=.09$ orta derecede korelasyon etkisini ve $\mathrm{R} 2=.25$ büyük korelasyon etkisini temsil etmektedir. Şekilden anlaşıldığı üzere IP'nin yapının doğrusal olmayan tepki parametreleri üzerinde yüksek korelasyon etkisi $(\mathrm{R} 2=0.51)$ vardır. Diğer bir deyişle, IP, yapısal tepkideki varyansın büyük bir oranını açıklamaktadır. Yüksek korelasyon etkisiyle beraber vektörel şiddet ölçüsünün $[\mathrm{Sa}(\mathrm{T} 1)$, IP(T1)], Tp/T1 etkisini de yakalandı̆̆ gözlemlenmiştir. Bu sonuçlar, IP’nin etkili ve verimli bir şiddet ölçüsü olduğunu doğrulamaktadır.

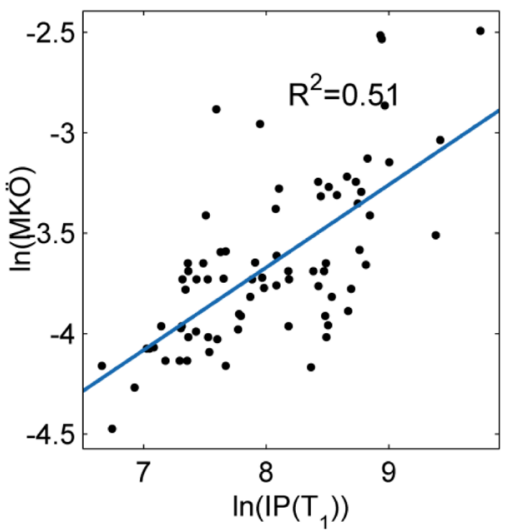

Şekil 7. $\mathrm{Sa}(\mathrm{T} 1)=0.4 \mathrm{~g}$ 'ye ölçeklendirilmiş darbeli ve darbesiz kayıtların yapısal tepkilerinin IP(T1) ile korelasyonu.

Bir şiddet ölçüsünün yapıların sismik performanslarını tahmin etmedeki verimliliği, yapısal tepkideki değişkenlik (saçılım) seviyesi ile ölçülebilir. Belirli bir şiddet ölçüsünde yapısal tepkinin log-normal dağıldığı varsayllarak tepki parametresinin medyan değeri ve standart sapması (sigma) hesaplanabilir. Vektörel şiddet ölçüsünün [Sa(T1), IP(T1)] kullanıldığında durumda ise $\mathrm{Sa}(\mathrm{T} 1)$ seviyesine ölçeklendirilmiş kaytllardan elde edilen yapısal tepki ile IP(T1) logaritmik değerlerine lineer regresyon analizi uygulanabilir ve koşullu standart sapma hesaplanabilir. Şekil $8, \mathrm{Sa}(\mathrm{T} 1)$ ve [Sa(T1), IP(T1)] şiddet ölçüleri kullanılarak tahmin edilen darbeli kayıt MKÖ standart sapmalarının farklı şiddet seviyelerindeki değerlerini göstermektedir. Sonuçlara göre, [Sa(T1), IP(T1)] şiddet ölçüsü, $\mathrm{Sa}(\mathrm{T} 1)$ şiddet ölçüsüne göre, MKÖ standart sapma değerini yaklaşık \%30-35 oranında azaltmıştır. IP'nin darbesiz kayitlar üzerindeki etkinliği ise Şekil 9'da gösterilmiştir. $\mathrm{Bu}$ analiz sonucunda da standart sapmanın yaklaşık $\% 25-30$ oranında azaldığı görülmüștür. Şekil 10,Sa(T1) ve $[\mathrm{Sa}(\mathrm{T} 1), \mathrm{IP}(\mathrm{T} 1)]$ şiddet ölçüleri kullanılarak tahmin edilen değiştirilmiş Park ve Ang hasar indisi standart sapmalarını farklı şiddet seviyelerindeki değerlerini darbeli kayıtlar için göstermektedir. IP şiddet ölçüsünün, hasar indisini tahmin etmede etkili olduğu sonucuna varılmıştır. Ancak, bu etkinliğin yüksek yer hareketi şiddet seviyesinde azaldığı görülmüştür.

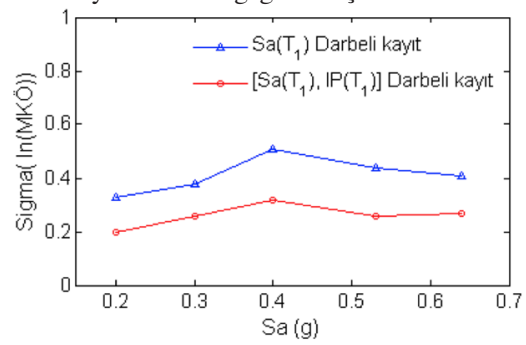

Şekil 8. $\mathrm{Sa}(\mathrm{T} 1)$ ve $[\mathrm{Sa}(\mathrm{T} 1), \mathrm{IP}(\mathrm{T} 1)]$ şiddet ölçüleri kullanılarak tahmin edilen darbeli kayıt MKÖ standart sapmalarının farklı şiddet seviyelerindeki değerleri.

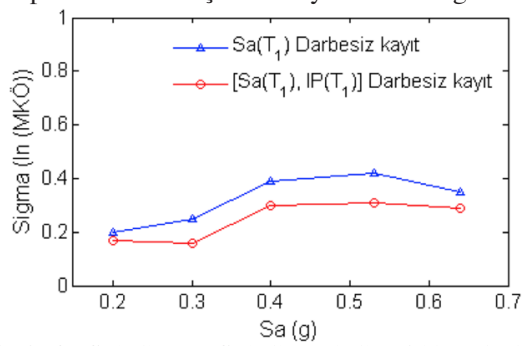

Şekil 9. $\mathrm{Sa}(\mathrm{T} 1)$ ve $[\mathrm{Sa}(\mathrm{T} 1), \mathrm{IP}(\mathrm{T} 1)]$ şiddet ölçüleri kullanılarak tahmin edilen darbesiz kayıt MKÖ standart sapmalarının farklı şiddet seviyelerindeki değerleri.

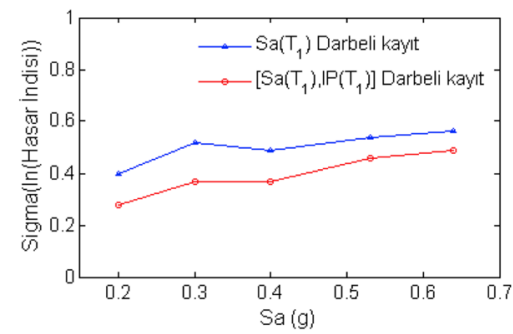

Şekil 10. $\mathrm{Sa}(\mathrm{T} 1)$ ve $[\mathrm{Sa}(\mathrm{T} 1), \mathrm{IP}(\mathrm{T} 1)]$ şiddet ölçüleri kullanılarak tahmin edilen darbeli kayit Hasar İndisi standart sapmalarının farklı şiddet seviyelerindeki değerleri 


\section{SONUÇLAR}

$\mathrm{Bu}$ çalışmada, [Sa(T1), IP(T1)] vektör şiddet ölçüsünün yakın saha depremlerine maruz kalan yapıların maksimum ve kümülatif yapı tepkilerini tahmin etmede etkin olduğu gösterilmiştir. Periyot bağımlı bir parametre olan Anlık Güç (IP(T1)), yakın saha deprem kayıtlarını yapıda etkili olması beklenen frekans aralığına göre karakterize etmekte ve darbeli yer harekeri karakteristik özelliklerinin (darbe periyodu ve darbe genliği) yapılar üzerindeki etkisini temsil etmektedir. Çalışmada yapılan analizler, IP'nin yapısal tepkideki varyansın büyük bir bölümünü açıkladığını göstermiştir. Bunlara ek olarak, [Sa(T1), IP(T1)] şiddet ölçüsünün yapısal değişkenliği azaltmada $\mathrm{Sa}(\mathrm{T} 1)$ şiddet ölçüsüne göre daha etkili olduğu sonucuna varılmıştır. Bu yüzden, önerilen şiddet ölçüsünün olasılıksal sismik tasarım ve değerlendirme yöntemlerine dahil edilmesi yapısal tepki tahminlerinin daha güvenilir ve doğru bir şekilde yapılmasını sağlayacaktır. 


\section{KAYNAKLAR}

Alavi, B., \& Krawinkler H (2000). Consideration of near-fault ground motion effects in seismic design. Proceedings of the 12th World Conference on Earthquake Engineering, 8.

Baker, J.W., \& Cornell, C.A (2008). Vector-valued intensity measures for pulse-like near-fault ground motions. Engineering Structures, 30(4):1048-1057.

Cohen, J. (1988). Statistical power analysis for the behavioral sciences. Hillsdale, NJ: Erlbaum.

Ibarra, L. F., Medina, R. A., \& Krawinkler, H. (2005). Hysteretic models that incorporate strength and stiffness deterioration, Earthquake Engineering \& Structural Dynamics, 34, 1489-1511.

Kunnath, S. K., Reinhorn, A. M., \& Lobo, R. F. (1992). IDARC Version 3.0: A program for the inelastic damage analysis of reinforced concrete structures, Tech. Rep, NCEER-92-0022, Buffalo, New York.

Lignos, D. (2008). Sidesway collapse of deteriorating structural systems under seismic excitations, Ph.D. Thesis, Stanford University.

Luco, N., Cornell C.A. (2007). Structure-specific scalar intensity measures for near-source and ordinary earthquake ground motions. Earthquake Spectra, 23(2):357-392.

Somerville, P.G., Smith, N.F., Graves, R.W., \& Abrahamson N.A. (1997). Modification of empirical strong ground-motion attenuation relations to include the amplitude and duration effects of rupture directivity. Seismological Research Letter., 68(1):199-222.

Tothong P, Luco, N. (2007). Probabilistic seismic demand analysis using advanced ground motion intensity measures. Earthquake \& Structural Dynamics, 36(13):1837-1860.

Zengin, E.,\& Abrahamson, N. A. (2020a). A vector-valued intensity measure for near-fault ground motions. Earthquake Engineering \& Structural Dynamics, 49(7), 716-734.

Zengin, E.,\& Abrahamson, N. (2020b). Conditional Ground-Motion Model for Damaging Characteristics of Near-Fault Ground Motions Based on Instantaneous Power. Bulletin of the Seismological Society of America, 110(6), 2828-2842.

Zengin, E., Abrahamson, N. A., \& Kunnath, S. (2020). Isolating the effect of ground-motion duration on structural damage and collapse of steel frame buildings. Earthquake Spectra, 36(2), 718-740. 